DOSSIÊ: Homeschooling e o Direito à Educação

\title{
Educação na casa: perspectivas de desescolarização ou liberdade de escolha?
}

\section{Education at home: unschooling prospects or freedom of choice?}

(i) Universidade do Estado do Rio de Janeiro, Rio de Janeiro, RJ, Brasil. maria2.celi@gmail.com.

Resumo: O estudo objetiva analisar como a educação doméstica na atualidade tem sido tratada por autores que examinam o tema, sinalizando perspectivas de desescolarização relacionadas ao projeto neoliberal de sociedade, em oposição à alegada liberdade de escolha das famílias. Em um plano mais específico, é abordada a discussão norte-americana sobre o assunto, partindo da premissa que, no Brasil, a opção pelo homeschooling está ligada à forte influência dessa prática existente nos Estados Unidos da América. Os procedimentos teóricometodológicos são aqueles relativos à pesquisa qualitativa, essencialmente bibliográfica, que tem como referência os escritos de Paraskeva (2010) e Torres Santomé (2003). Conclui-se com a exposição de parte das questões suscitadas no debate relativo ao fato de casa e escola coexistirem na sociedade como espaços legitimados para ensinar, indicando a tensão entre a tendência de desescolarização e o declarado direito dos pais de decidir sobre a educação dos filhos.

Palavras-chave: educação doméstica, desescolarização, homeschooling, projeto neoliberal, liberdade de escolha 


\section{pro.posıções}

Abstract: The study focuses on domestic education today, in order to analyze how it has been dealt with by authors who examine the issue, signaling prospects of unschooling related not to the alleged freedom of choice of families, but to the neoliberal project of society. Specifically, the paper addresses the American discussion on the subject, assuming that in Bravil, the option for bomeschooling is strongly influenced by this existing practice in the United States. The theoretical and methodological procedure is an essentially bibliographic qualitative research, which references the writings of Paraskeva (2010) and Torres Santomé (2003). It concludes with a partial exposition of the issues raised in the debate on the fact that home and school coexist in society as legitimate spaces for teaching, indicating the tension between the trend of unschooling and the professed right of parents to decide on their children's education.

Keywords: domestic education, unschooling, homeschooling, neoliberal project, freedom of choice

\section{Introdução}

O artigo faz uma análise da configuração da educação doméstica ${ }^{1}$ na atualidade, buscando compreender como esse movimento tem sido tratado por autores que examinam o assunto, localizando perspectivas de desescolarização relacionadas ao projeto neoliberal de sociedade, confrontadas à liberdade de escolha das famílias.

Em um plano mais específico, são apresentadas algumas abordagens que envolvem, na contemporaneidade, a discussão relativa às motivações e às implicações sobre a educação realizada na própria casa dos aprendizes, convencionalmente denominada como homeschooling. Essa modalidade, que pode ser realizada pelos pais ou, para ensinar aquelas disciplinas que eles não dominam, por professores contratados, havendo ${ }^{2}$ sites que cadastram

\footnotetext{
${ }^{1}$ Com base nas pesquisas realizadas anteriormente pela autora (Vasconcelos, 2005, 2006, 2009, 2011, 2014), as denominações utilizadas neste estudo são: "educação doméstica", quando se trata da concepção da prática de ensinar os filhos e as filhas no ambiente doméstico; "ensino domiciliar" quando há referências aos Projetos de Lei sobre o assunto, tendo em vista que, de modo geral, essa é a nomenclatura usada nos ordenamentos jurídicos; e "educação na casa", opção mais recorrente, que se refere à sua equiparação/inversão à "educação na escola", cuja subjetividade é diferente da abrangida por "educação em casa", ou seja, essa prática é exposta como educação formal realizada na própria casa do aluno. Cabe notar que os termos convencionados para as referências à escola são aqueles dos quais a educação doméstica toma emprestado os que se aplicam às suas especificidades, tendo em vista que ainda não há uma palavra em português para denominar os praticantes de homeschooling (Vasconcelos, 2005, 2011).

${ }^{2}$ Sobre os sites, consultar https://www.time4learning.com/homeschool/teacher_to_homeschooler.shtml
} 


\section{pro.posıções}

10.1590/1980-6248-2015-0172

$e$-ISSN 1980-6248

docentes para esse fim, tem nos Estados Unidos da América ${ }^{3}$, seu maior número de adeptos, assim como normatizações rigorosas para a sua adoção.

A referência à nomenclatura e a discussão norte-americana sobre o tema partem da premissa de que, no Brasil, constata-se uma forte influência das concepções e dos métodos praticados nos Estados Unidos e no Canadá entre famílias que optam pelo homeschooling, influência essa que, mesmo quando não está relacionada à opção inicial, aparece posteriormente nos modelos e nos manuais utilizados, por serem os mais amplamente disponíveis.

Os procedimentos metodológicos utilizados referem-se a uma pesquisa de natureza qualitativa, essencialmente bibliográfica, cuja revisão da literatura privilegiou autores norteamericanos ou os que escrevem sobre essa realidade, tendo em vista que, além da influência notadamente registrada nas práticas de homeschooling no Brasil, há um intenso debate sobre esse tema nos países da América do Norte, considerando o avanço e a consolidação das práticas de educação doméstica. Nessa perspectiva, destacam-se, como principais fontes, textos tanto de autores que defendem essa problemática como uma estratégia educativa (Lyman, 2000; Ray, 2005), quanto daqueles que criticam o movimento ${ }^{4}$, por considerá-lo uma "ameaça à escolarização pública" (Torres Santomé, Paraskeva, \& Apple, 2003). Cabe ressaltar, ainda, que o artigo em pauta compõe um estudo mais amplo sobre o assunto, a partir do qual são tomados aspectos específicos relacionados à literatura citada, confrontando-a ao debate contemporâneo, no sentido de demonstrar conveniências e obstáculos entre o particular (a família) e o público (o Estado) para a aceitação/negação do homeschooling como uma modalidade de educação, destacando-se, como fontes principais, textos de autores que enfocam esta mesma problemática.

\footnotetext{
3 A referência aos Estados Unidos da América justifica-se não apenas pela nomenclatura de homeschooling, já convencionada em países de outras línguas, mas pelo fato de ser essa modalidade aceita nos 50 estados americanos, embora haja restrições rigorosas em alguns deles. De acordo com Barbosa (2013, p. 27), nos Estados Unidos, atualmente, “o homeschooling está fundamentado no entendimento de que sua prática é uma entre as várias escolhas possíveis para os pais norte-americanos".

4 A opção pela palavra "movimento" deve-se à sua utilização ser recorrente para definir esse fenômeno, tanto pelos defensores e usuários do homeschooling como por seus detratores e críticos.
} 


\section{pro.posições}

$e$-ISSN 1980-6248

Em que pese não haver prescrição legal no Brasil para o oferecimento do ensino domiciliar $^{5}$, durante a realização da pesquisa (Vasconcelos, 2011; Vasconcelos \& Morgado, 2014), verifica-se o avanço acelerado, tanto de famílias interessadas em ensinar os filhos na casa, como da frequência com que a mídia tem aberto espaço para a sua divulgação, trazendo para o cenário a discussão das concepções que sustentam essa prática, sobretudo as de alguns autores que entendem o homeschooling como parte de um projeto neoliberal de reformas.

O texto discute, a seguir, a progressiva tensão entre a tendência de desescolarização, considerada decorrente de um projeto neoliberal consolidado em muitos países, e o declarado direito dos pais de decidir sobre a educação dos filhos, identificando, como consequência, a possibilidade de estes espaços - casa e escola - coexistirem na sociedade como legitimados para ensinar.

\section{Do discurso da liberdade de escolha ao projeto de reforma neoliberal}

Após mais de meio século de hegemonia do sistema de escolarização, Canário (2005, p. 59) localiza a "crise da escola" nos anos de 1960, resultante, entre outros fatores, do fato de ela estar "desarmada perante a massificação" e sem outra ideologia justificante que não fosse o "prometido destino profissional dos alunos". Tais dificuldades encontram, a partir dos anos de 1990, as ilimitadas possibilidades tecnológicas de acesso ao conhecimento, o que delineia um cenário ideal de ruptura com a institucionalização do ensino e coroa uma tensão que já se arrastava por décadas.

Muito embora os processos de rejeição definitiva à escola ainda atinjam uma pequena proporção da população nos países em que o homeschooling conquistou adeptos (Barbosa, 2013; Kloh, 2014; Ribeiro, 2011; Vasconcelos, 2011), o simples fato de sua opção ser real entre as classes que, até então, foram usuárias convictas dos processos escolares expõe o tênue limite que se apresenta ao início da desescolarização da sociedade, desencadeando um conflito explícito entre os partidários de um e outro sistema.

\footnotetext{
5 Ensino domiciliar é a terminologia utilizada em grande parte dos Projetos de Lei (PL) apresentados no Parlamento brasileiro visando à previsão legal dessa modalidade de educação. O último deles é o PL n. 3.261/2015, de autoria do deputado Eduardo Bolsonaro.
} 


\section{pro.posıções}

$e$-ISSN 1980-6248

Grosso modo, a contestação mais veemente à possibilidade de desescolarização, para além dos recorrentes discursos de socialização - cada vez mais pálidos diante da dimensão virtual que se torna inerente às relações contemporâneas -, surge, de maneira evidente, relacionada a objeções de natureza política. Os detratores referem-se ao homeschooling como parte das reformas neoliberais, constando da agenda da nova gestão pública desse contexto, e constituindo-se em uma meta de descentralização no gerenciamento dos sistemas educativos, sem precedentes, após o advento da escolarização (Paraskeva \& Au, 2010; Torres Santomé et al, 2003).

Ainda que a educação na casa já possua, hoje, inúmeros adeptos, espalhados por diversos países, comunidades organizadas e, especialmente, teóricos e pesquisadores a tratar desse tema, há também, numa proporção igual ou maior, aqueles que condenam intensamente tais práticas, pois consideram que a escolarização, com seus sistemas instituídos, foi uma conquista dos últimos séculos que trouxe inquestionáveis progressos para a sociedade e qualquer alternativa que rompa com a sua formatação seria inaceitável, sob a justificativa de que é preciso melhorar a qualidade da escola, mas, em nenhuma hipótese, desescolarizar a sociedade. Nessa argumentação, incluem-se, ainda, fatores listados como pouco prováveis de serem superados pelas limitações físicas e socializantes do ambiente doméstico, que fundamentam a principal ponderação pedagógica para o impedimento legal das práticas de homeschooling (Barbosa, 2013; Cury, 2006, 2009).

Contudo, sob a alegação de ser a liberdade - um princípio básico dos direitos humanos -, e a liberdade de escolha - um direito dos pais sobre a educação de seus filhos -, trava-se um duelo entre essas duas correntes, no qual, apesar dos aspectos políticos e pedagógicos envolvidos, não se pode desconsiderar que a perspectiva da educação na casa volta à cena como uma possibilidade real, à medida que as tecnologias da informação e da comunicação disponíveis aproximam o conhecimento dos sujeitos e tornam a intermediação da escola, por vezes, dispensável, rompendo, assim, com os limites físicos para a concretude do processo de escolaridade.

Os adeptos do movimento ${ }^{6}$ de educação na casa ganham popularidade no início dos anos de 1980, especialmente nos Estados Unidos da América, e espalham-se pelos

6 A opção pela palavra "movimento" deve-se ao fato de sua utilização ser recorrente, tanto pelos defensores e usuários do homeschooling, como por seus detratores e críticos, para definir esse fenômeno. 


\section{pro.posıções}

$e$-ISSN 1980-6248

continentes, havendo registros, nas décadas seguintes, de experiências de educação doméstica em todo o mundo. De acordo com os dados apresentados por Ray (2005), em seu Worldwide guide to homeschooling. Facts and stats on the benefits of homeschooling, no início do século XXI, em 2002, haveria famílias “educando seus filhos em casa nos Estados Unidos, Canadá, México, País de Gales, Inglaterra, Alemanha, Polônia, Suíça, Japão, Austrália e África do Sul” (p. 8) 7 . Segundo o mesmo autor (Ray, 2005), no final da década, em 2010, esses números atingiram mais de dois milhões de crianças e jovens submetidos à educação na casa, somente nos Estados Unidos.

Composto ainda por outra vertente, cuja nomenclatura utilizada é unschooling ${ }^{8}$ (objeção escolar), ou desescolarização num sentido mais estrito, o movimento continuou a crescer de maneira significativa, segundo o National Home Education Research Institute ${ }^{9}$, autor de várias pesquisas de acompanhamento e análise deste fenômeno em nível internacional. Para isso, poderiam ser consideradas diversas motivações, cujo ponto em comum seria, em boa parte dos casos, a oposição às leis e ao sistema de escolarização vigente e obrigatório.

As famílias que recorrem à educação na casa, portanto, normalmente, estariam também buscando uma formação diferente daquela oferecida pelas escolas, seja por motivos religiosos, filosóficos, contextuais, especiais ou circunstanciais. Ainda nessa perspectiva, o discurso dos defensores do homeschooling possui argumentos baseados em teóricos da desescolarização, entre eles, Ivan Illich e John Holt. Illich é autor da obra Deschooling society (1973), na qual propõe que se desescolarize a sociedade e que se evite que fundos governamentais sejam aplicados neste fim, desestabilizando o sistema de escolarização, assim como havia sido feito na separação da igreja do estado. Segundo Illich (citado por Holt \& Farenga, 2003, p. 60), dever-se-ia alterar a Constituição dos países para proibir o

\footnotetext{
${ }^{7}$ Os textos consultados escritos originalmente em inglês têm tradução livre realizada pela autora.

8 Também conceituado como aprendizagem direcionada pela criança e aprendizagem natural, o termo unschooling foi originalmente usado por John Holt. Transformado em método para o ensino doméstico, significaria "nada de escola". Unschooling é considerado ainda um dos métodos do ensino doméstico, muito bem aceito por famílias norte-americanas e europeias. As crianças que seguem o ensino doméstico não vão à escola para aprender. Toda a aprendizagem é feita "a partir de casa". O unschooling é mais livre, apregoando que, na aprendizagem, as crianças devem seguir os seus próprios ritmos. A aprendizagem torna-se simplesmente uma parte natural da vida. Todos os dias é a criança que decide o que quer fazer, "se quer ir à biblioteca ler sobre baleias ou passar o dia fazendo experiências científicas na cozinha” (Holt \& Farenga, 2003, pp. 61-62).

${ }^{9} \mathrm{O}$ National Home Education Research Institute foi fundado pelo seu atual presidente, Brian D. Ray, também editor, desde 1985, da revista acadêmica Home School Researcher. Oferece estatísticas, investigações e relatórios técnicos sobre esta opção de educação na casa. Recuperado em 6 de agosto de 2015, de https://www.nheri.org/
} 


\section{pro.posições}

$e$-ISSN 1980-6248

estabelecimento de educação como um princípio legal. John Holt, por sua vez, passou parte de sua vida ${ }^{10}$ tentando descobrir maneiras de operar essas mudanças, porém percebeu que a maioria das pessoas jamais concordaria com o fim do financiamento das escolas do governo e procurou outras formas de avançar em direção ao objetivo de "empowering", ou preparar as pessoas para crescer sem escolaridade. Para Holt (1976) (citado por Holt \& Farenga, 2003), as escolas possuíam poder suficiente "para causar dor mental e física às crianças, para ameaçá-las, atemorizá-las e humilhá-las” (p. 204).

Para os mais envolvidos no movimento, o homeschooling compara-se a uma revolução, como sugere Lyman (2000) no seu livro The homeschooling revolution. A autora examina o que chama de "as grandes diferenças entre educação escolar em casa e na escola pública" (p. 115) e caracteriza o homeschooling como um "movimento popular por dissidentes pais-educadores que estão ensinando os seus filhos a ler e escrever em mesas da cozinha” (p. 115). Segundo ela, esses pais estariam tornando aceitável o que é considerado, até então, uma ideia da contracultura: "os pais dedicados têm alcançado seus objetivos sem muitos aplausos e sem um centavo de financiamento do governo" (p. 115).

Lyman (2000) descreve a educação pública como um "sistema de coação baseado em um monopólio bem organizado, financiado por impostos confiscatórios” (p. 20). Afirma ainda que as crianças de escolas públicas têm pouco ou nenhum controle sobre o seu tempo ou contatos sociais, e que devem submeter-se a um conjunto de "normas draconianas": cursos exigidos pelo Estado, requisitos de atendimento e agrupamentos por idade, sendo incapazes de escapar da doutrinação ideológica lenta, ou da ação de professores malformados, ou rudes, e da violência dos colegas. A autora cita a pesquisa que ajudou a popularizar o movimento do homeschooling moderno, realizada por Raymond Moore e John Holt, na qual Holt via as escolas como "lugares que produzem cidadãos obedientes, tediosos e despreparados" (p. 23). Ela mostra ainda que, com relação aos resultados, nos casos pesquisados, independentemente de raça ou renda familiar, "as crianças bomeschooled obtinham maior pontuação em testes padronizados do que seus colegas de escola pública" (p.87).

\footnotetext{
${ }^{10}$ John Holt, professor da Universidade de Harvard, foi um dos grandes promotores da ideia de desescolarização em todo o mundo. Seu ativismo dava-se, especialmente, por meio da revista Growing Without Schooling [Desenvolvendo-se sem escola], da qual foi fundador e articulista.
} 


\section{pro.posıções}

10.1590/1980-6248-2015-0172

$e$-ISSN 1980-6248

$\mathrm{Na}$ vertente oposta, os críticos ao bomeschooling, ou a qualquer outra forma de educação que a separe do Estado como mantenedor, supervisor ou legislador, também apresentam uma vasta argumentação, que vai desde conceber a educação na casa como um movimento que surge no bojo das políticas neoliberais de enfraquecimento do Estado, até defender a ideia, comumente usada como princípio da negação, de que só é possível haver socialização entre crianças e jovens por intermédio da escolarização.

Entre esses críticos, destaca-se Torres Santomé (2003, p. 35) que, no livro Ventos de desescolarização. A nova ameaça à escolarização pública credita à repercussão dos discursos contra a escola pública e, em especial, contra o professorado da rede pública, o "fenômeno" da "escola em casa". Segundo o autor, o discurso do homeschooling serviria às intenções dos representantes da teoria econômica neoliberal, porque traz à luz muitos dos "modos incorretos da escola", denunciando como certos professores e professoras não cumprem as suas tarefas, como a burocracia se apodera dos modos de funcionamento na instituição e como as famílias e os alunos têm dificuldades de se sentirem integrados. O movimento da "escola em casa" contribuiria, assim, para reforçar a estratificação social, econômica, política e cultural, ou seja, incrementaria as desigualdades, além do que "as fracturas sociais" acabariam ficando mais evidentes (p. 40).

Ainda com base nos escritos de Torres Santomé (2003), um dos argumentos mais utilizados para convencer as famílias dos benefícios do bomeschooling seria o de que, ao longo da história, foi a família a instância educadora que ensinava tudo o que era preciso para sobreviver. Contrariando esse discurso, o autor chama atenção para as limitações da educação doméstica, baseada em aulas particulares e na convivência apenas com os pais, impedindo que as crianças e jovens experimentem as relações/interações que estão postas na sociedade.

Na prática, a opção "escola em casa" [ênfase no original] é uma educação na base de aulas particulares, onde só existe um aluno e, neste caso, o pai e \ou a mãe faz tanto papel de pai e \ou mãe como de docente; assume os dois papéis. Pelo contrário, a educação numa instituição escolar obriga a estabelecer um maior número de relações; as aulas agrupam, normalmente, entre 20 a 25 estudantes cada; nestas, os rapazes e as raparigas caracterizam-se por possuir distintos ritmos de aprendizagem, diferente bagagem cultural, expectativas díspares, diferentes capacidades e modalidades de inteligência, distinto sexo, etc., algo que converte esse grupo numa pequena representação do que é o mundo externo à aula, no qual eles vivem. (Torres Santomé, 2003, p. 46) 


\section{pro.posições}

$e$-ISSN 1980-6248

O autor afirma que aqueles que optam por esse modelo de "escolaridade em casa" seriam, principalmente, famílias de "muito alto status econômico, cultural e social", além de possuírem "valores muito tradicionais", entre os quais "a mulher prefere não trabalhar por um salário fora de casa e, fundamentalmente, crentes" (Torres Santomé, 2003, p. 47).

Para Torres Santomé (2003, p. 47), embora os conteúdos curriculares trabalhados na "educação em casa" sejam aqueles que regem a escolarização nas escolas tanto públicas como privadas, as famílias não seguem a mesma sequência, "nem põem a ênfase nas mesmas interpretações e valorizações; incidem mais no pensamento crítico, mas partindo de uma notável censura informativa para que não se cheguem a pôr em questão as ideologias partilhadas pelo casal” (p. 47).

Quanto aos resultados favoráveis alardeados nas pesquisas relativas ao homeschooling, Torres Santomé (2003) acredita que eles seriam obtidos, por essas crianças, em qualquer outra escola pública ou privada, o que não aconteceria com os grupos sociais mais desfavorecidos, pois "seria muito difícil que os seus filhos e filhas obtivessem melhores resultados acadêmicos que os daqueles que acodem às redes públicas ou privadas de ensino” (p. 48).

A análise cética do autor em relação ao homeschooling assinala que tais práticas acontecem preferencialmente nos grupos conservadores religiosos e antifeministas, entre outros, que rejeitam as concepções evolucionistas da vida, bem como os conteúdos que venham a questionar as suas tradições e seus modos de vida, tais como o papel tradicional da mulher e de filhos e filhas. Além disso, esses grupos não aceitariam que o professorado se preocupasse em socializar os alunos e as alunas para dotá-los de maior sensibilidade para a diversidade e utilizassem nas aulas metodologias mais cooperativas. Sofreriam de um "pânico moral", promovido pela imprensa mais sensacionalista (Torres Santomé, 2003, p. 49).

Torres Santomé (2003) acrescenta que "uma das consequências ocultas, tanto deste movimento antiescolar, como dos que defendem e promovem o ensino privado" (p.51), é que ambos serviriam para "abrir alas a todos os grupos empresariais e classes mais favorecidas que pedem menos impostos e uma maior redução no gasto público" (p. 51).

Em que pesem os elementos contundentes da argumentação do autor que não podem ser desconsiderados sob nenhuma hipótese, ao reunir os interesses das famílias que praticam o homeschooling, aos dos defensores, e quiçá, mantenedores do ensino privado, cabe refletir se 


\section{pro.posições}

$e$-ISSN 1980-6248

essas instâncias poderiam compactuar dos mesmos objetivos e das mesmas concepções relativas ao "lugar" da educação, diante da pergunta de quem seriam os maiores perdedores em termos de receitas lucrativas originárias das escolas privadas, uma vez que, como sublinha o próprio Torres Santomé (2003), o “ensino em casa” é, essencialmente, preferido pelas classes sociais mais favorecidas.

No Brasil, por exemplo, onde o ensino domiciliar não tem regulamentação específica na legislação vigente, os resultados do Censo Escolar, datado de 2013 (INEP, 2013), oferecem números significativos a serem incorporados nesse debate: "nos 190.706 estabelecimentos de educação básica do País estão matriculados 50.042.448 alunos, sendo que 41.432 .416 (82,8\%) em escolas públicas e 8.610 .032 (17,2\%) em escolas da rede privada” (p.12). Comparando esses dados aos do ano de 2012, no que se refere à educação básica, o Censo afirma que houve uma queda de 1,9\% nas matrículas da rede pública e, em contrapartida, a rede privada cresceu 3,5\%, o que demonstra um aumento considerável de um ano para outro.

Para a associação dos dados apresentados à localização dos usuários do homeschooling, cabe reportar o estudo de Sampaio e Guimarães (2009), Diferenças de eficiência entre ensino público e privado no Brasil, que, ao analisar, sob uma metodologia específica, a eficiência dos estabelecimentos de ensino público e privado no Brasil, conclui que, na amostra de colégios analisados, há uma grande disparidade entre os colégios privados e públicos no País. Essa segmentação, aferida entre o sistema público e privado de educação básica, indicaria que cada rede tem um alunado próprio, cuja mobilidade estaria relacionada, especialmente, às condições econômicas das famílias a que pertencem.

Considerando a existência dessa segmentação no sistema escolar brasileiro, no qual haveria uma distinção entre as classes que frequentam o ensino escolar público e o privado, pode-se supor que os pretensos adeptos do homeschooling no Brasil, provavelmente, não seriam oriundos da escola pública, mas, sim, da escola privada. É nela que estariam os pais com condições econômicas, culturais e sociais suficientes para se encarregar da educação dos filhos, preparando-os não só para realizar as avaliações decorrentes das regulamentações que, normalmente, são exigidas para a prática do homeschooling - como forma de manter um mecanismo de controle por parte do Estado -, mas também para ministrar e supervisionar aulas e lições cotidianas, com disponibilidade para que um membro da família se dedique a essa tarefa, deixando o mercado de trabalho. 


\section{pro.posições}

$10.1590 / 1980-6248-2015-0172$

$e$-ISSN 1980-6248

Portanto, a priori, não parece possível que os grupos empresariais mantenedores de escolas privadas, no Brasil, possam ter seus interesses reunidos aos dos defensores do homeschooling. Todavia, no caso brasileiro, a diminuição da interferência, do controle e da fiscalização do Estado sobre a educação, com o consequente enfraquecimento do primeiro, certamente aproxima os interesses dos setores privados aos dos adeptos do movimento homeschooling, muito embora não se possa prever qual será a reação dos grupos empresariais que oferecem educação básica a qualquer permissão que venha a ser dada à possibilidade de educar na casa, particularmente quando perceberem qual clientela irá aderir a esse movimento. O que já se observa no setor educacional privado é uma corrida para a obtenção de autorizações, concedidas pelo Estado, para o funcionamento de cursos de educação a distância em todos os níveis e modalidades permitidos. Tal fenômeno, entre outros, pode sugerir, com base no que já ocorre em outros países como os Estados Unidos da América, os rumos que cercam a educação, especialmente, a privada.

\section{A escola charter e a agência socializante entre os protagonistas do}

\section{debate}

Indubitavelmente, o movimento de educação na casa caracteriza-se por uma oposição à escolaridade, por vezes independente das condições de qualidade apresentadas, ainda que o discurso de defesa do homeschooling tenha utilizado, como justificativa recorrente, a exposição das fragilidades e dos problemas observados na escola pública. No entanto, esse discurso pode estar mais relacionado às oportunidades aferidas pelo "senso comum" para advogar seus propósitos, do que, na realidade, àquilo que venha a se constituir como motivador da opção das famílias pelo bomeschooling, como indica Paraskeva (2010), quando assinala que a crise e as situações de ruptura que as escolas têm enfrentado teriam o intuito de descredibilizar o ensino público, "começando a despertar, ao nível do senso comum, a noção de que o que é público é mau e o que é privado é bom" (p. 37).

A alegada insatisfação com a escola pública seria, portanto, mais uma repetição de palavras de ordem afeitas ao "senso comum" do que a condição determinante desse movimento, pois o bomeschooling estaria muito mais relacionado às escolhas das classes sociais 


\section{pro.posições}

$e$-ISSN 1980-6248

médias e altas, descritas anteriormente por Torres Santomé (2003), do que às possibilidades dos usuários das redes públicas. Assim, a crítica dos adeptos da educação na casa não seria dirigida apenas à escola pública, mas, neste caso, à escola privada, que também não atenderia às expectativas das famílias.

De toda forma, para Paraskeva (2010), o homeschooling, sejam quais forem os grupos que o acolham, faria parte das reformas neoliberais e teria seus interesses e objetivos identificados aos projetos de "escolas charter", os quais deveriam ser percebidos como "a recredibilização da educação formal" por parte da agenda neoliberal, colocando em causa muitos dos princípios mais elementares da educação pública e contribuindo para a multiplicação dos desequilíbrios sociais. Segundo o autor,

tal como podemos constatar, tanto os projectos escolas charter quanto os programas homeschooling se impõem como ferramentas da estratégia neoliberal que passa pela diminuição progressiva, não só do poder, como também do papel social da escola, enquanto instituição pública. No fundo, estamos perante estratégias de privatização dos benefícios e socialização dos custos. (p. 37)

No que se refere às escolas charter, de acordo com o Canada's Charter Schools: Initial Report, a primeira surgiu no estado de Minnesota, em 1991 (Paraskeva, 2010), e se constituem como escolas autônomas, "isentas de muitas leis e regulações estaduais e locais, em troca de maior responsabilidade financeira e acadêmica" (Barbosa, 2013, p. 27), além de destinadas a realizar inovações no domínio organizativo e curricular, com o intuito de melhorar a aprendizagem dos alunos, embora a eficácia dependa, fundamentalmente, do clima regulador e da assistência técnica, que são da responsabilidade do governo.

Quando Paraskeva (2010) reúne a concepção do homeschooling a das escolas charter, para efeito de crítica às reformas neoliberais levadas a cabo nos últimos anos, demonstra que o movimento de escolarização na casa e o surgimento de outra proposta organizativa de escola são consequências diretas da reação às instituições escolares e não somente à escola pública, o que acaba por corroborar a afirmação de muitos autores que defendem o bomeschooling, quando ressaltam a incapacidade da escola tanto pública como privada de atender aos seus fins (Clements, 2004; Holt \& Farenga, 2003; Kunzman, 2009a; Kunzman, 2009b; Lyman, 2000; Ray, 2005). 


\section{pro.posıções}

Cabe ressaltar que, na linha de frente das implicações negativas levantadas sobre o homeschooling aparece, de forma recorrente, a insuficiência de socialização, processo que não poderia ocorrer de maneira satisfatória senão no ambiente escolar, onde as crianças convivem com as diferenças e se acostumam com as trocas e as interações que fazem parte da vida em sociedade. De acordo com Cury (2006), em artigo intitulado "Educação escolar e educação no lar: espaços de uma polêmica”, a família não dá conta das inúmeras formas de vivência de que todo o cidadão participa e é levado a participar:

$\mathrm{Na}$ consolidação de formas coletivas de convivência democrática a educação escolar dada em instituições próprias de ensino torna-se uma importante agência de socialização secundária para a vida social e formação da personalidade. ... Ela faz parte da denominada socialização secundária como uma esfera pela qual, junto com outras, a pessoa vai sendo influenciada (e influindo) por meio de grupos etários, da inserção profissional, dos meios de comunicação, dos espaços de lazer, da participação em atividades de caráter sócio-político-cultural, entre outros. (pp. 670-671)

Para o autor, a escola seria como uma "agência socializante", que propiciaria "tanto a transmissão do acúmulo de conhecimentos por meio do desenvolvimento de capacidades cognoscitivas quanto a transmissão de normas, valores, atitudes relativas à vida social" (Cury, 2006, p. 671). Além disso, segundo Cury, "a educação escolar responderia a um dos pilares da igualdade de oportunidades" (p. 671), o que fortaleceria as possibilidades de mobilidade social. Dessa forma, enfatiza, "não se pode deixar de apontar que a educação dada em família, em momento existencial de forte exigência de convívio social, responsabiliza os pais das teses ligadas à home schooling pelas lacunas que a falta da escola implica” (p. 685).

Cury (2006) reitera a necessidade do que ele denomina de "cultura relativa à obrigatoriedade", para fazer frente ao movimento de desescolarização que se difunde, com base no dever do Estado como promotor de uma cidadania solidária e participante da vida sociopolítica. Para o autor,

é preciso explicitar, justificar as razões dessa obrigatoriedade e insistir na importância do ensino fundamental na faixa etária prevista em lei, com a devida presença dos alunos em instituições próprias de ensino presencial em vista do pleno desenvolvimento do educando $(\mathrm{LDB}$, art.2). (p. 686)

Torres Santomé (2003), por sua vez, ao construir sua argumentação relativa ao "pânico moral" que assolaria a sociedade contemporânea, sinaliza que outra motivação para a opção 


\section{pro.posıções}

$e$-ISSN 1980-6248

das famílias pelo homeschooling seria consequência das mudanças culturais aceleradas, o que levaria os membros desses coletivos a idealizarem o passado, imaginando que qualquer tempo pretérito foi melhor que o presente, e, portanto, seria necessária "uma educação que volte a disciplinar as novas gerações para obedecer acriticamente às pessoas adultas" (p. 49). Para Torres Santomé (2003), os defensores da “educação em casa” seriam grupos nostálgicos que lutariam para que se promovessem e ensinassem concepções de mundo, valores e posturas de acordo com um passado idealizado e inexistente. Segundo esse autor, citando Apple (2000),

Integram também este movimento de apoio à 'escola em casa' aqueles que desde posições neoliberais estão tratando de minar o Estado e as suas instituições, para que as normas que regem o mundo da produção se convertam nas únicas legítimas, afectando assim toda a forma de inter-relação humana. (p.49)

O conflito maniqueísta tantas vezes presente em nossa sociedade, dicotomizando o "velho" e o "novo", o "certo" e o "errado", o "valioso" e o "inválido", novamente parece retornar ao cenário da educação, dessa vez com a garantia de que algo irá transformar os nexos, para além das reformas até então empreendidas.

No que diz respeito ao debate posto nos dias atuais, muitas são as implicações que envolvem o tema, mas não há dúvida de que o movimento de desescolarização avança com a propaganda de um novo modo de vida e de educação para as crianças e jovens, permeado pelas tecnologias disponíveis, ainda que pressionado pela ameaça de conversão do homeschooling em mais uma etapa de consolidação da lógica neoliberal sobre o sistema escolar.

\section{À guisa de conclusão...}

A inserção da prática do homeschooling no bojo da doutrina político-econômica neoliberal, muito mais do que a convergência de interesses entre seus partidários e os adeptos da educação na casa, é provável que tenha, inicialmente, encontrado eco na lógica descrita por Pedroni (2003), que considera "tudo o que é público negativo e tudo que é privado positivo" (p. 7). No entanto, numa etapa posterior a essa, quando o setor privado não ofereceu as respostas e/ou não atendeu às expectativas das famílias, partiu-se para uma terceira perspectiva, na qual a família toma para si, novamente, a tarefa que, em determinado 


\section{pro.posıções}

$e$-ISSN 1980-6248

momento, foi delegada ao Estado. Por outro lado, para o Estado que tenta eliminar sua posição no tecido social, o movimento das famílias para assumir esse papel é visto e narrado positivamente como uma suposta liberdade de escolha, da qual não se pode privar os pais da opção sobre a educação dos filhos e filhas.

Além disso, a proclamada crise da escola abriu uma extensa lacuna, a qual, como em nenhum outro momento, pode ser preenchida por uma modalidade alternativa: a educação na casa. No entanto, como alerta Paraskeva (2003), "o sistema educacional está sempre em crise" (p. 12) e torna-se fácil o argumento que imputa à escola a culpa pelas crises que, normalmente, são derivadas da gestão da economia conduzida pelo Estado.

Em síntese, "numa época em que o Estado-providência revela incapacidade de liderança" (Paraskeva, 2003, p. 81) e a agenda das políticas educacionais tem como eixos condutores a autonomia, a privatização, a competitividade, a descentralização, entre outros padrões dominantes, os que veem o homeschooling como um movimento identificado com a doutrina neoliberal constatam que, indubitavelmente, ele possui uma característica eficaz de sedução, como programa “acessível” (p.86), com bons resultados, e que já engloba milhões de pessoas em todo o mundo.

Com todas as contradições que se apresentam à discussão desse tema, o que não seria diferente tratando-se de um contexto tão complexo, é forçoso concluir que, como os autores Paraskeva, 2010, Pedroni, 2003 e Torres Santomé, 2003 sinalizam, por trás da tão alardeada liberdade de escolha, é possível haver interesses que pretendem mais do que o controle sobre a educação dos filhos. Ao mesmo tempo, cada autor, sob a sua argumentação, chama a atenção para o lugar que a mídia tem ocupado na difusão de exemplos e modelos de educação doméstica, não estando insensível à grande adesão que as matérias sobre o assunto despertam em diferentes segmentos da população, com ênfase para camadas altas e médias, cujas gerações anteriores atravessaram o período hegemônico da escola, vivenciando suas vicissitudes e dificuldades.

Como cenário do palco onde essa "abordagem dramática” (Burke, 2008, p. 52) se desenrola, está a "a ameaça satânica", levantada por Apple (2003, p. 121) para ilustrar os receios manifestados pelas famílias e seus medos de destruição da ordem moral e da liberdade pessoal, que desintegra o mundo à sua volta, atribuídos não a causas político-econômicas 


\section{pro.posições}

$e$-ISSN 1980-6248

como a globalização destrutiva e as decisões de uma elite econômica que transforma todas as coisas em mercadorias. "Em vez disso, as causas são transferidas para aquelas instituições e pessoas que estão constantemente a ser fustigadas pelas mesmas forças” (Apple, 2003, p. 122), entre elas as escolas.

A perspectiva oposta, por sua vez, considera que os atores que obstaculizam a liberdade de escolha e a legalidade do homeschooling atuam como agentes de um mundo estatizado que voltaria a assombrar aqueles que nunca o compreenderam.

Como afirmam Vasconcelos e Morgado (2014), a realidade exige um posicionamento, pois se torna cada vez mais difícil mostrar-se indiferente a essas questões. Todavia, romper com a relação compulsória entre todos os sujeitos e a escola talvez contenha um risco maior do que aqueles já indicados pelo projeto neoliberal de reformas, uma vez que a aspirada liberdade de escolha pode deixar lacunas que, na desincumbência do Estado, permitirão a ascensão de outros espaços de profusão ideológica, espaços esses, talvez, mais difíceis de serem dissecados e analisados em suas fragilidades, do que a escola. 


\section{pro.posıções}

$e$-ISSN 1980-6248

\section{Referências}

Apple, M. W. (2003). A extinção dos professores: a política cultural do ensino em casa. In J. Torres Santomé, J. M. Paraskeva, \& M. W. Apple (Orgs.), Ventos de desescolarização. A nova ameaça à escolarização pública (pp. 116-141). Lisboa: Plátano.

Barbosa, L. M. R. (2013). Ensino em casa no Brasil: um desafio à escola? Tese de Doutorado, Faculdade de Educação da Universidade de São Paulo, São Paulo, SP, Brasil.

Burke, P. (2008). O que é história cultural? (2a ed.). Rio de Janeiro: Zahar.

Canário, R. (2005). O que é a escola? Um “olhar” sociológico. Porto: Porto Editora.

Clements, A. D. (2004). Homeschooling. A research-based how-to manual. Lanham, New York, Toronto, Oxford: Rowman \& Littlefield Education.

Cury, C. R. J. (2006). Educação escolar e educação no lar: espaços de uma polêmica. Revista Educação e Sociedade. 27(96), 667-688.

Cury, C. R. J. (2009). A desoficialização do ensino no Brasil: a Reforma Rivadávia. Revista Educação e Sociedade. 30(108), 717-738.

Holt, J. (1976). Libertad y algo más: ¿ ‘hacia la desescolarización de la sociedad? Buenos Aires: El Ateneo.

Holt, J., \& Farenga, P. (2003). Teach your own - The John Holt book of homeschooling. Cambridge, USA: Perseus Publishing.

Illich, I. (1973). Por que devemos desinstalar a escola. In I. Illich, Sociedade sem escolas (pp. 16-39). Petrópolis: Vozes.

Instituto Nacional de Estudos e Pesquisas Educacionais Anísio Teixeira - INEP. (2014). Censo Escolar da Educação Básica 2013 [resumo técnico]. Brasília: INEP.

Kloh, F. F. P. (2014). Homeschooling no Brasil: a legislação, os projetos de lei e as decisões judiciais. Dissertação de Mestrado em Educação, Universidade Católica de Petrópolis, Petrópolis, RJ, Brasil.

Kunzman, R. (2009a). Understanding homeschooling: A better approach to regulation, Theory and research in Education, 7(3), 311-330. 


\section{pro.posıções \\ $e$-ISSN 1980-6248}

Kunzman, R. (2009b). Write these laws on tour children: inside the world of conservative Christian homeschooling. Boston: Beacon Press.

Lyman, I. (2000). The homeschooling revolution. Amherst, Massachusetts: Bench Press International.

Paraskeva, J. M. (2010). Privatização dos benefícios e socialização dos custos. Dos chequesensino ao homeschooling. In J. M. Paraskeva, \& W. Au, (Orgs.), O direito à escolha em educação. Cheques-ensino, projectos charter e o ensino doméstico (pp.17-53). Mangualde, PT: Edições Pedagogo.

Paraskeva , J. M., \& Au, W. (Orgs.) (2010). O direito à escolha em educação. Cheques-ensino, projectos charter e o ensino doméstico. Mangualde, PT: Edições Pedagogo.

Pedroni, T. (2003). Introdução crítica. In J. Torres Santomé, J. M. Paraskeva, \& M. W. Apple (Orgs.), Ventos de desescolarização. A nova ameaça à escolarização pública (pp 5-14). Lisboa: Plátano.

Ray, B. D. (2005). Worldwide guide to homeschooling. Facts and stats on the benefits of homeschooling. Nashville, Tennessee: Broadman \& Holman Publishers.

Ribeiro, Á. M. C. (2011). O ensino doméstico e a organização escolar: um contributo sociológico-organizacional sobre a realidade portuguesa. Dissertação de Mestrado em Ciências da Educação, Universidade do Minho, Braga, Portugal.

Sampaio, B., \& Guimarães, J. (2009). Diferenças de eficiência entre ensino público e privado no Brasil. Revista Economia Aplicada, 13(1), 1-14.

Torres Santomé, J. (2003). Escola e família: duas instituições em confronto? In J. Torres Santomé, J. M. Paraskeva, \& M. W. Apple (Orgs.), Ventos de desescolarização. A nova ameaça à escolarização pública (pp. 15-56). Lisboa: Plátano Editora.

Torres Santomé, J., Paraskeva, J. M., \& Apple, M. W. (Orgs.). (2003). Ventos de desescolarização. A nova ameaça à escolarização pública. Lisboa: Plátano.

Vasconcelos, M. C. C. (2005). A casa e os seus mestres: a educação no Brasil de oitocentos. Rio de Janeiro: Gryphus. 


\section{pro.posıções}

$e$-ISSN 1980-6248

Vasconcelos, M. C. C. (2006). De volta à casa: revisitando as possibilidades da educação diante das novas tecnologias. In S. Bustamante (Org.), Educação e tecnologia: caminhos para a inclusão digital (pp. 7-19). Rio de Janeiro: Publit Soluções Editoriais.

Vasconcelos, M. C. C. (2009). A educação na casa: uma prática das elites portuguesas e brasileiras no século XIX. In D. B. de Souza, \& S. A. Martinez (Orgs.), Educação Comparada Brasil-Portugal: rotas do além mar (pp. 130-150). São Paulo: Xamã.

Vasconcelos, M. C. C. (2011). Relatório de estágio pós-doutoral. Relato de investigação apresentado à Universidade do Minho para a certificação de estudos de pósdoutoramento, Braga, Portugal.

Vasconcelos, M. C. C., \& Morgado, J. C. B. C. (2014). Desafios à escolarização obrigatória: a inserção do homeschooling na legislação educacional no Brasil e em Portugal. Revista Brasileira de Política e Administração da Educação, 30(1), 203-230.

Submetido à avaliação em 27 de janeiro de 2016; aceito para publicação em 31 de maio de 2016. 